from fifty to one hundred thousand cylinders need to be renewed each month.

Tests have shown that by sand-blasting the glazed cylinders for two or three minutes, using No. 90 steel grit and an air pressure of 15-20 lb., a surface was formed that in many ways was superior to the original. The reduction in cylinder diameter due to this resurfacing is less than 0.002 in. Cylinders treated in this manner have had hard service in Bell Laboratories for more than six months without showing need for further treatment. Cylinders that have been ground have a grooved structure, while sand-blasted cylinders have an irregular pattern of minute projections that grips the paper firmly in all directions. The sand-blasting, moreover, knocks out the fine particles of filler compound that otherwise would reduce the friction between paper and cylinder, much as talcum powder would. Typewriter cylinders vary considerably in size, but on the ordinary letterpage machine the rubber weighs about $1 \mathrm{lb}$, and with more than a million replacements a year, sandblasting promises a considerable saving of rubber compound.

\section{Cancer Mortality}

The June issue of the Statistical Bulletin, the organ of the Metropolitan Life Insurance Company of New York, contains an editorial based on a series of observations extending over a number of decades, from which the following conclusions emerge. While the recorded mortality among males from all forms of cancer has shown an increase by about one third in the course of thirty years, the rate among females has changed but little. Towards the end of the period there has been some improvement among females, while there has been a slackening in the upward trend for males. The result has been that the rates for males and females at ages 1-74 which widely differed in 1911-15 have converged to a common level of 86.8 per 100,000 in the quinquennium 1936-40. A substantial cause of the rise in cancer mortality among males is probably due to improved diagnosis-a supposition confirmed by a consideration of the mortality from cancer of the various organs. Since 1911 mortality of cancer of the peritoneum, intestines and rectum has practically doubled in the case of males and increased by about 50 per cent in females. The mortality from cancer of the pancreas and prostate has also risen sharply. The rise in the death-rate from cancer of the lung and pleura has been attributed to improvement in diagnostic technique. The most hopeful outlook occurs in the case of those organs which are readily accessible such as the female genital organs, the skin and mouth, in each of which the mortality has declined since 1911. Cancer of the breast is exceptional in that, in spite of its accessibility, its mortality has increased during the thirty years. The improvement due to early recognition and treatment of suspected growths is illustrated by the fact that the American College of Surgeons has records of more than 36,000 cases of so-called "cured" cancer.

\section{Health of the United States Army}

According to the War Department, the army training in the United States is in better health than ever during war-time. It is anticipated that the general hospital admission rate in 1942 will be about 10 per cent lower than in 1941. Venereal disease is substantially less than during the War of 1914-18, the syphilis rate being the lowest in army history. The total venereal diseases rate was 40.5 per 1,000 men in 1941 and 38 per 1,000 during the first six months of 1942. Throughout 1941 and thus far in 1942, the death-rate has been the lowest in army history. During this period, from one half to two thirds of the deaths resulted from external causes such as traffic accidents. The meningitis fatality rate in the army is far below that in civil life. The malaria rate per 1,000 men in the Continental United States was only 0.61 for the first eight months of 1942 as compared with $1 \cdot 24$ in 1941 . Universal vaccination has virtually eliminated smallpox, and rigid sanitary control and inoculation have rendered typhoid almost non-existent. The incidence of scarlet fever is now extremely low.

\section{Public Health in Brazil}

The September issue of the Boletin de la Oficina Sanitaria Panamericana contains an article by Dr. João de Barros Barreto, director-general of the National Department of Health, Rio de Janeiro, who states that this department has the following sections : administrative service; divisions of public health and hospital organization; Oswaldo Cruz institute for the study of prevalent diseases and the manufacture of sera, vaccines and chaulmoogra esters; national services for leprosy, tuberculosis, yellow fever, malaria, plague, mental diseases, control of medicine, port sanitation, water and sewerage, and vital statistics, and since September 23, 1942, the national service for cancer. Courses in public health are given by the National Health Department and include microbiology, immunology and parasitology, vital statistics, physiology, urban and rural sanitation, epidemiology and prophylaxis, industrial, child and mental hygiene, nutrition and public health organization and administration. A number of scholarships are granted to medical men through the Panamerican. Sanitary Office.

\section{Fevers in the Sudan}

THE recently published report, for 1940, of the Director of Medical Services of the Sudan, contains an account of an epidemic of yellow fever which broke out in that country in July and continued until the end of 1940. The number of known cases was 15,633, of which 1,627 were fatal. The real incidence was probably greater as many of the cases were mild and atypical, and therefore were not notified. The epidemic was particularly remarkable in that, so far as was known, yellow fever had never occurred previously in the Sudan or indeed in any part of the Old World east of the centre of Africa. The report also contains an account of a Iong-continued epidemic of relapsing fever which started in 1936 and reached its peak in 1940 with 1,487 cases. It is a remarkable fact that though relapsing fever is louse-spread, no mention is made in this report or any of its predecessors of typhus, so that this disease seems to be absent from the Sudan.

\section{Books on Historical Medicine and Science}

THE firm of Schuman's, 20 East 70th Street, New York, has recently issued a catalogue "Medical Miscellany List ' $F$ ' ", containing a number of interesting books and periodicals of which the following may be 
mentioned: Sir Benjamin Brodie's "Physiological Researches" (1851), Edwin Chadwick's "Report on the Sanitary Condition of the Labouring Population of Great Britain" (1843), A. Weismann's "Vorträge über Deszendenztheorie" (1904), first edition of Gray's "Anatomy" (1858), William Hamilton's "Observations on the Preparation, Utility and Administration of Digitalis Purpurea or Foxglove" (1807), Francis Home's "Medical Facts and Experiments" (1759), Hufeland's "Art of Prolonging Life" (1797), Lord Lister's "Contributions to Physiology and Pathology" (1859), Thomas Bateman's "Reports on the Diseases of London, and the State of the Weather from 1804 to 1816" (1819), Puschmann's "Handbuch der Geschichte der Medizin" (1902-1905), the first two volumes of Archiv für Physiologie (1796 -97 ) and a number of runs of the Lancet from 1848 until 1871.

\section{Recent Earthquakes}

DURING the third quarter of 1942 , the epicentres of ten strong earthquakes have been found chiefly from instrumental data from American observatories. The first four epicentres in July and August were determined at St. Louis by the Jesuit Seismological Association, and the others in August and September by the United States Coast and Geodetic Survey, in co-operation with the Jesuit Seismological Association and Science Service. On July 8 the epicentre was in Chile $\left(24 \cdot 5^{\circ} \mathrm{S} ., 69 \cdot 5^{\circ} \mathrm{W}\right.$.) with a depth of focus near $175 \mathrm{~km}$. A later earthquake on July 8 and one on July 12 had their epicentres near the coast of Ecuador $\left(0 \cdot 3^{\circ} \mathrm{S} ., 80 \cdot 2^{\circ} \mathrm{W}\right.$.) and a depth of focus near $500 \mathrm{~km}$. The latter was reported felt at Guayaquil. On August 6 the earthquake had its epicentre in the Pacific Ocean off the coast of Central America $\left(12 \cdot 9^{\circ}\right.$ N., $92 \cdot 1^{\circ}$ W. $)$. On August 23 a shock had its epicentre in the Pacific Ocean between the Kam. chatka Peninsula and the Aleutian Islands $\left(51.5^{\circ} \mathrm{N}\right.$, $163^{\circ}$ E.). Further shocks in the same region were on September $2\left(52.5^{\circ}\right.$ N., $170^{\circ}$ W.), September 4 $\left(52 \cdot 8^{\circ} \mathrm{N},{ }^{2}, 169 \cdot 2^{\circ} \mathrm{W}.\right)$, and September $9\left(53 \cdot 1^{\circ} \mathrm{N}\right.$., $165^{\circ} \mathrm{W}$.). Sequences of shocks in this manner are not uncommon and the present group is somewhat to the west of a similar group some months ago. The shock of August 24 had its epicentre near the coast of Peru $\left(14 \cdot 5^{\circ} \mathrm{S} ., 75 \cdot 5^{\circ} \mathrm{W}\right.$.) with a depth of focus between $50 \mathrm{~km}$. and $100 \mathrm{~km}$. A further earthquake with its epicentre in the Pacific Ocean off Central America $\left(12 \cdot 5^{\circ}\right.$ N., $91^{\circ}$ W.) occurred on September 4. On Thursday, October 29, an earthquake was felt in Western Turkey, including Istanbul and Smyrna. No damage has been reported.

\section{A New Comet}

A COMET was discovered by Oterma on Sept. 1ld. 23h. Its position at the time of discovery was R.A., 23h. 51m., Dec. $+6^{\circ} 20^{\prime}$, and its magnitude was 13. A later telegram announces that the comet was observed again on Nov. $6 \mathrm{~d} .20 \mathrm{~h} .16 \mathrm{~m}$., and its position then was R.A., $4 \mathrm{~h}$. $11 \mathrm{~m}$., Dec. $-0^{\circ} 47^{\prime}$. Its magnitude had not altered. It was stated to be moving slowly northward. An orbit will be computed when $a$ third position is obtained.

\section{The Night Sky in December}

New moon occurs on December 8 d. 01 h. $59 \mathrm{~m}$. U.T., and full moon on December 22d. 15h. $03 \mathrm{~m}$. Conjunctions during the month are as follows: Dec. 6d. 13h., Mars in conjunction with the moon, Mars $5^{\circ} \mathrm{S}$.; Dec. 20d. 17h., Saturn in conjunction with the moon, Saturn $3^{\circ}$ N.; Dec. 24d. 13h., Jupiter in conjunction with the moon, Jupiter $3^{\circ} \mathrm{N}$. Occultations of stars brighter than magnitude 6 are as follows, the times referring to Greenwich :

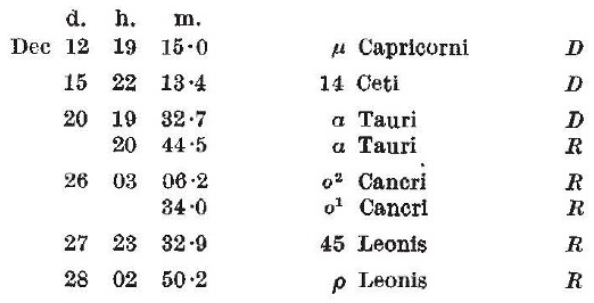

Mercury, Venus and Mars are not well placed for observation during the month. Jupiter, in Gemini, souths at $2 \mathrm{~h} .10 \mathrm{~m}$. about the middle of the month and is well placed for observation. Saturn, in Taurus, souths at $22 \mathrm{~h}$. $50 \mathrm{~m}$. in the middle of the month and can be observed all night. The Geminid meteor shower is active during December $7-15$, the radiant being close to $\alpha$ Geminorum. The winter solstice commences Dec. 22d. $12 \mathrm{~h}$.

\section{Announcements}

THE Minister of Supply has appointed Prof. J. E. Lennard-Jones, Plummer professor of theoretical chemistry in the University of Cambridge, to be chief superintendent of armament research, and Mr. F. E. Smith, of Imperial Chemical Industries, Ltd., to be chief engineer and superintendent of armament design. These appointments have resulted from the recommendations of a committee under the chairmanship of Dr. H. L. Guy recently appointed by the Minister of Supply to review the machinery for the conduct of research, design, and experimental work in connexion with the development of guns, small arms, and ammunition.

Dr. C. D. Darlington, director of the John Innes Horticultural Institution, has been invited to deliver lectures to the Mendelian Society of Lund in Sweden. $\mathrm{He}$ will journey to Sweden under the auspices of the British Council, and, in addition to his lectures at Lund, will speak on cytology to learned societies in other centres, and will also deliver a number of general lectures on a broad biological topic.

The Earl of Moray and Mr. J. M. Bannerman have been appointed members of the Forestry Commission in succession to Sir John Sutherland, who has submitted his resignation, and to fill another existing vacancy. At the request of the Secretary of State for Scotland, Sir John Sutherland has agreed to continue to attend meetings of the Commission so that his experience may be available when matters relating to Scotland are discussed.

The council of the Royal Meteorological Society has awarded the Buchan Prize for 1943 to Dr. T. E. W. Schumann and Mr. Gordon Manley. The Prize is awarded biennially to the authors of the papers published in recent issues of the Society's Quarterly Journal which have been adjudged to contain the most important original contributions to meteorology. 